\title{
Assessment of knowledge of reproductive health of adolescent school girls from 13-16 years with special reference to HIV-AIDS
}

\author{
Pradnya P. Sathe ${ }^{1 *}$, Prachi P. Sathe ${ }^{2}$, Shubhalaxmi D. Kotnis ${ }^{1}$, Mangulikar S.K. ${ }^{1}$
}

\begin{abstract}
${ }^{1}$ Department of Community Medicine, Dr.V.M. Governement Medical College, Solapur, Maharashtra, India
${ }^{2}$ Department of Paediatrics, Bombay Port Trust Hospital, Wadala, Mumbai, Maharashtra, India
\end{abstract}

Received: 30 November 2015

Accepted: 18 December 2015

\author{
*Correspondence: \\ Dr. Pradnya P. Sathe, \\ E-mail: pradnyasathe_14@yahoo.com
}

Copyright: ( $)$ the author(s), publisher and licensee Medip Academy. This is an open-access article distributed under the terms of the Creative Commons Attribution Non-Commercial License, which permits unrestricted non-commercial use, distribution, and reproduction in any medium, provided the original work is properly cited.

\begin{abstract}
Background: Adolescent period includes the age group of 10-19 years. This period is crucial as many important physiological changes like puberty occur during this period. Menarche is an important milestone in a girl's life and appropriate knowledge about safe and hygienic practices regarding menstruation and reproductive health as well as HIV is necessary to prevent adverse outcomes. The main aim and objective of this study is to ;(1) To assess the level of awareness about reproductive health among adolescent school girls aged 13 to16 years and (2) To compare awareness between girls from Municipal school and Private school.

Methods: This study was conducted on a convenient sample of 176 adolescent school girls from two English Medium Schools located in Mumbai. The girls were of age group 13-16 years from class IX and X. School 'A' catering girls from low socio-economic class and school ' $\mathrm{B}$ ' to higher socio-economic class.

Results: Study showed that $9.4 \%$ of school A and $25.4 \%$ of school B had appropriate knowledge about pubertal changes. $77.1 \%$ from school A and $43.1 \%$ from school B practiced restrictions during menses. 51.2\% got information about menses from their mothers. Only $13.5 \%$ from school A and 40.2\% from school B had knowledge about family planning. $76.1 \%$ girls had heard of HIV.

Conclusions: Knowledge regarding reproductive health and HIV-AIDS was significantly more in school B than in school A.
\end{abstract}

Keywords: Adolescent, Reproductive health, HIV-AIDS, Knowledge

\section{INTRODUCTION}

Adolescence is the period of transition from childhood to adulthood. WHO has defined adolescence as the age group of 10-19 years. ${ }^{1}$ The first menstruation (menarche) occurs between 11 and 15 years with a mean of 13 years. The onset of menstruation is one of the most important changes occurring among girls during adolescent years. But due to various myths, misconceptions and restrictions practiced during menstruation, adolescent girls often develop negative attitudes towards this natural physiological phenomenon. ${ }^{2}$ Majority of the girls lack scientific knowledge about menstruation and puberty. Adolescent girls often are reluctant to discuss this topic with their parents and often hesitate to seek help regarding their menstrual problems. ${ }^{3}$

Unhygienic menstrual practices may affect their health such as increased vulnerability to reproductive tract infections (RTI). The interplay of socio-economic status, menstrual hygiene practices and RTI are noticeable. ${ }^{3}$ 
Women having better knowledge regarding menstrual hygiene and safe practices are less vulnerable to RTI and its consequences. Therefore, increased knowledge about menstruation right from middle school may escalate safe practices and may help in mitigating the suffering of millions of women. ${ }^{1}$

The main reasons of STIs/HIV in young people include biological factors, high risk sexual behaviour patterns (early initiation of sex, premarital sex, bisexual orientation and multiple sexual partners), transmission dynamics and treatment-seeking behaviour. Women, have a higher incidence of STIs than men because of their greater biological susceptibility. The lack of STI education in India is a major concern, particularly in schools. $^{4}$

Information about behaviour, attitudes, and knowledge through regular surveys is essential to better understand the dynamics of the STI epidemic. This information is also important in assessing changes over time as a result of prevention efforts. The aim of the present study is to evaluate adolescent school girls' knowledge, perceptions and attitudes towards menstruation, family planning, contraception, STIs/HIV, safer sex practice and sex education and to explore their current sexual behaviour in India. ${ }^{4}$ The main aim and objective of the study is (1)To assess the level of awareness about reproductive health among adolescent school girls aged 13 to16 years and (2)to compare awareness between girls from Municipal school and Private school.

\section{METHODS}

\section{Study area}

This observational study was conducted in adolescent girls from two English medium schools located in Mumbai, India School A catering to low socio-economic class and School B catering to high socio-economic class.

\section{Study population, sample size and sample technique}

A convenient sample size of 176 girls was considered for this study, 74 from school A and 102 girls from school B. These girls were belonging to class IX and X. This study was conducted over a period six months from April 2011 to September 2011.

\section{Data collection technique and tools}

A written permission was taken from the Principals of both the schools. A written Consent was obtained from the parents of the girls. All the girls were interviewed personally using a questionnaire. The questions were explained to them in their most preferred language and responses were recorded in the pre-structured proforma. The knowledge of reproductive health and HIV / AIDS was assessed with regards to physiological changes during puberty, menstruation, misconception regarding menstruation, hygiene practices during menstruation, contraception and sex education, mode of transmission and prevention of HIV.

\section{Inclusion criteria}

- Age group: 13 to 16 years.

- Standard: IX and X.

\section{Exclusion criteria}

The exclusion criterion for this study were nil.

\section{Data analysis}

The data was analysed using Chi square test. The results obtained were analysed using the Chi-Square Test. A 'p' value of $<0.05$ was considered significant.

Before carrying out this study, the thesis protocol was approved by Ethics committee of the hospital.

\section{RESULTS}

Maximum number of girls belonged to age group between $14-14.9$ years; 35 (47.3\%) from school A and 50 (49\%) from school B. The highest age of the girl was 16.1 years and lowest was 13.8 years. Mean ages of the girls were comparable in both the groups.

The term 'Appropriate' for the present study was defined as knowledge regarding all of the components of pubertal changes in girls such as increase in height, weight, hip size, breast development, development of acne, growth of pubic and axillary hair, mood changes, attainment of menarche. The girls who could tell all the components were marked as 'Appropriate' answer and those who could say some of the components were marked to have 'incomplete' knowledge. Table 1 and Figure 1 shows that $7(9.4 \%)$ from school A and $25(24.5 \%)$ from school B had appropriate knowledge about pubertal changes. This difference was statistically significant.

Table 1: Knowledge about pubertal change.

\begin{tabular}{|llll|}
\hline Parameters & $\begin{array}{l}\text { School A } \\
(\%)\end{array}$ & $\begin{array}{l}\text { School B } \\
(\%)\end{array}$ & $\begin{array}{l}\text { Total } \\
\text { N=176 }\end{array}$ \\
\hline \multirow{2}{*}{ Appropriate } & $\begin{array}{l}* 07 \\
(09.4 \%)\end{array}$ & $\begin{array}{l}25 \\
(24.5 \%)\end{array}$ & $\begin{array}{l}32 \\
(18.2 \%)\end{array}$ \\
\hline \multirow{2}{*}{ Incomplete } & $\begin{array}{l}54 \\
(73.0 \%)\end{array}$ & $\begin{array}{l}68 \\
(66.7 \%)\end{array}$ & $\begin{array}{l}122 \\
(69.3 \%)\end{array}$ \\
\hline \multirow{2}{*}{ No idea } & $\begin{array}{l}13 \\
(17.6 \%)\end{array}$ & $\begin{array}{l}09 \\
(08.8 \%)\end{array}$ & $\begin{array}{l}22 \\
(12.5 \%)\end{array}$ \\
\hline \multirow{2}{*}{ Total } & 74 & 102 & 176 \\
& $(100 \%)$ & $(100 \%)$ & $(100 \%)$ \\
\hline
\end{tabular}

By Chi - Square test $* \mathrm{P}<0.05$ Significant.

Table 2 shows that a total of $146(92.9 \%)$ of the girls had some knowledge about menstruation prior to menarche; 
$51(68.9 \%)$ from school A as compared to $95(93.1 \%)$ from school B which was statistically significant.

Table 3 shows that a total of $131(74.4 \%)$ girls said that there was an effect of mental tension on their menstrual bleeding pattern; 53 (71.6\%) from school A as compared to $78(76.5 \%)$ from School B. The difference in the two groups was not significant.

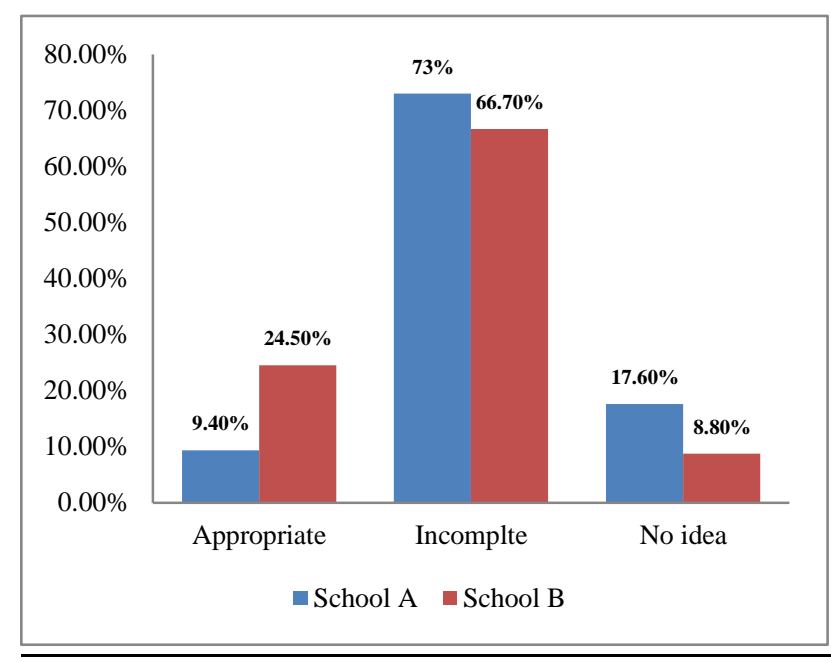

Figure 1: Knowledge about pubertal change.
Table 2: Knowledge prior to menstruation.

\begin{tabular}{|llll|}
\hline Parameter & $\begin{array}{l}\text { School A } \\
(\%)\end{array}$ & $\begin{array}{l}\text { School B } \\
(\%)\end{array}$ & Total \\
\hline Yes & $* 51(68.9 \%)$ & $95(93.1 \%)$ & $146(92.9 \%)$ \\
\hline No & $23(31.1 \%)$ & $7(6.9 \%)$ & $30(17.1 \%)$ \\
\hline Total & $74(100 \%)$ & $102(100 \%)$ & $176(100 \%)$ \\
\hline
\end{tabular}

A total of $101(57.4 \%)$ girls had restriction to their activity during menses; 57 (77\%) from School A which were significantly more as compared to $44(43.1 \%)$ from School B. The restrictions were mainly in the form of staying at home, not going for play outside home, not visiting holy places.

This data reveals that a total of $78(44.2 \%)$ girls had restriction of food during menses; 60 (81.1\%) from School A which were significantly more as compared to $18(17.6 \%)$ from School B. When asked specifically that which type of food they usually avoid, the common answers were jiggery, meat, groundnuts, papaya etc.

Table 4 and Figure 2 reveal that maximum number 101 (57.4\%) of girls got information about menstruation from their friends; followed by mother in 90 (51.2\%) girls; 26 (35.1\%) from school A and $64(62.7 \%)$ from school B and this difference was statistically significant. The books and magazines were the least common $2(1.1 \%)$ source of information about menstruation.

Table 3: Stress and practices during menstruation.

\begin{tabular}{|lccl|}
\hline Parameters & School A (\%) & School B (\%) & Total $(\%)$ \\
\hline Effect of mental tension on menses & $53(71.6 \%)$ & $78(76.5 \%)$ & $131(74.4 \%)$ \\
\hline Restriction of physical activity & $* 57(77 \%)$ & $44(43.1 \%)$ & $101(57.4 \%)$ \\
\hline Restriction of food & $* 60(81.1 \%)$ & $18(17.6 \%)$ & $78(44.2 \%)$ \\
\hline No restriction & Nil & Nil & Nil \\
\hline
\end{tabular}

By Chi - Square Test $* \mathrm{P}<0.05$, Significant.

Table 4: Source of information about menstruation.

\begin{tabular}{|c|c|c|c|}
\hline Source & $\begin{array}{l}\text { School A } \\
(\%)\end{array}$ & $\begin{array}{l}\text { School B } \\
(\%)\end{array}$ & Total \\
\hline Friends & $\begin{array}{l}42 \\
(56.8 \%)\end{array}$ & $\begin{array}{l}59 \\
(57.8 \%)\end{array}$ & $\begin{array}{l}101 \\
(57.4 \%)\end{array}$ \\
\hline Mother & $\begin{array}{l}26 \\
(35.1 \%)\end{array}$ & $\begin{array}{l}* 64 \\
(62.7 \%)\end{array}$ & $\begin{array}{l}90 \\
(51.2 \%)\end{array}$ \\
\hline Television & $\begin{array}{l}* 10 \\
(13.5 \%)\end{array}$ & $\begin{array}{l}27 \\
(26.5 \%)\end{array}$ & $\begin{array}{l}37 \\
(21.1 \%)\end{array}$ \\
\hline $\begin{array}{l}\text { School } \\
\text { teacher }\end{array}$ & $\begin{array}{l}5 \\
(6.8 \%)\end{array}$ & $\begin{array}{l}10 \\
(9.8 \%)\end{array}$ & $\begin{array}{l}15 \\
(8.5 \%)\end{array}$ \\
\hline $\begin{array}{l}\text { Books/ } \\
\text { Magazines }\end{array}$ & $\begin{array}{l}0 \\
(0 \%)\end{array}$ & $\begin{array}{l}2 \\
(1.1 \%)\end{array}$ & $\begin{array}{l}2 \\
(1.1 \%)\end{array}$ \\
\hline
\end{tabular}

By Chi - Square Test $* \mathrm{P}<0.05$, Significant.

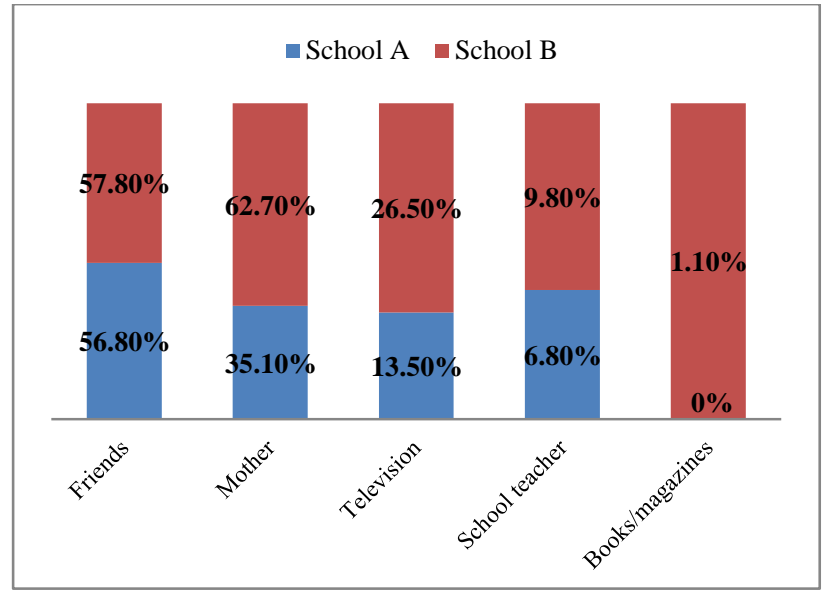

Figure 2: Sources of information about menstruation. 
Table 5 shows that a total of $168(95.4 \%)$ girls were having regular bath to maintain their hygiene during menses, 70 (94.6\%) were from school A and 98 (96.1\%) were from school B. The difference was not significant. Out of 167 (94.8\%), 69 (93.2\%) girls from School A practiced hand washing to maintain hygiene which was less as compared to $98(96.1 \%)$ from School B. Out of $111(63.1 \%)$ girls, $29(39.2 \%)$ girls from School A practiced washing genitalia with soap and water for hygiene during menses which was significantly lower than $82(80.4 \%)$ from School B.

Table 5: Knowledge about hygienic practices during menses.

\begin{tabular}{|lccc|}
\hline Hygiene & School A (\%) & School B (\%) & Total $(\%)$ \\
\hline Taking regular bath & $70(94.6 \%)$ & $98(96.1 \%)$ & $168(95.4 \%)$ \\
\hline Hand washing after using toilet & $69(93.2 \%)$ & $98(96.1 \%)$ & $167(94.9 \%)$ \\
\hline Frequently changing pads & $59(79.7 \%)$ & $90(88.2 \%)$ & $149(84.6 \%)$ \\
\hline Washing genitalia with soap and water & $* 29(39.2 \%)$ & $82(80.4 \%)$ & $111(63.1 \%)$ \\
\hline
\end{tabular}

By Chi - Square Test $*$ P $<0.05$, Significant.

Table 6 shows that a total of $99(56.2 \%), 49(66.2 \%)$ girls from School A and as compared to 50 (49.0\%) from School B believed that menstruation cleans the body of dirty blood which was significantly more. A total of 73 $(41.5 \%)$ girls considered menstruation make women weak. Out of them $40(54.1 \%)$ of the girls were from school A and 33(32.4\%) were from school B. Out of total $150(85.2 \%)$ girls, $62(83.8 \%)$ from School A and 88 (86.3\%) from School B knew that menses make women capable of child bearing.

Table 6: Believes regarding menstruation.

\begin{tabular}{|lccl|}
\hline Statement & School A (\%) & School B (\%) & Total (\%) \\
\hline Going to holy places should be avoided during menses & $66(89.2 \%)$ & $90(88.2 \%)$ & $156(88.6 \%)$ \\
\hline Menses make women capable of child bearing & $62(83.8 \%)$ & $88(86.3 \%)$ & $150(85.2 \%)$ \\
\hline Menstruation cleans the body of dirty blood & $* 49(66.2 \%)$ & $50(49.0 \%)$ & $99(56.2 \%)$ \\
\hline Menstruation makes women weak & $* 40(54.1 \%)$ & $33(32.4 \%)$ & $73(41.5 \%)$ \\
\hline
\end{tabular}

By Chi - Square Test* P $<0.05$, Significant .

In this study the answer 'complete knowledge' was marked for those who correctly said that 'Family planning' means; (i) Keeping gap of at least 3 to 4 years between two pregnancies and (ii) Use of contraceptive methods to delay the pregnancy.

The answer 'Partial knowledge' was marked when the girls gave either of the two answers.

Table 7: Knowledge about Family Planning.

\begin{tabular}{|llll|}
\hline Knowledge & $\begin{array}{l}\text { School A } \\
(\%)\end{array}$ & $\begin{array}{l}\text { School B } \\
(\%)\end{array}$ & $\begin{array}{l}\text { Total }(\%) \\
\text { Complete }\end{array}$ \\
$\begin{array}{l}* 10 \\
(13.5 \%)\end{array}$ & $\begin{array}{l}41 \\
(40.2 \%)\end{array}$ & $\begin{array}{l}51 \\
(29 \%)\end{array}$ \\
\hline \multirow{2}{*}{ Partial } & 39 & 37 & 76 \\
& $(52.7 \%)$ & $(36.3 \%)$ & $(43.2 \%)$ \\
\hline Do not & 25 & 24 & 49 \\
know & $(33.8 \%)$ & $(23.5 \%)$ & $(27.8 \%)$ \\
\hline \multirow{2}{*}{ Total } & 74 & 102 & 176 \\
& $(100 \%)$ & $(100 \%)$ & $(100 \%)$ \\
\hline
\end{tabular}

By Chi - Square Test $* \mathrm{P}<0.05$, Significant .

Table 7 shows that a total of $51(29 \%)$ girls had complete knowledge about family planning; significantly more in school B than school A. A total of 49 (27.8\%) girls had no knowledge about family planning. 25 (33.8\%) from school A and 24 (23.5\%) from school B.

Table 8 shows that a total $134(76.1 \%)$ girls had heard about HIV/AIDS; 88 (86.3\%) of girls from School B which was significantly more as compared to $46(62.2 \%)$ from School A.

Table 8: Girls who have heard of HIV / AIDS.

\begin{tabular}{|llll|}
\hline Parameters & $\begin{array}{l}\text { School A } \\
(\%)\end{array}$ & $\begin{array}{l}\text { School B } \\
(\%)\end{array}$ & $\begin{array}{l}\text { Total } \\
(\%)\end{array}$ \\
\hline \multirow{2}{*}{ Yes } & $\begin{array}{l}46 \\
(62.2 \%)\end{array}$ & $\begin{array}{l}* 88 \\
(86.3 \%)\end{array}$ & $\begin{array}{l}134 \\
(76.1 \%)\end{array}$ \\
\hline \multirow{2}{*}{ No } & $\begin{array}{l}28 \\
(37.8 \%)\end{array}$ & $14(13.7 \%)$ & $\begin{array}{l}42 \\
(23.9 \%)\end{array}$ \\
\hline \multirow{2}{*}{ Total } & 74 & 102 & 176 \\
& $(100 \%)$ & $(100 \%)$ & $(100 \%)$ \\
\hline
\end{tabular}

By Chi - Square Test $* \mathrm{P}<0.05$, Significant.

Table 9 shows that the most common answer given was transmission of HIV through needles 98 (55.7\%) followed by infected blood $90(51.1 \%)$ and sexual contact $87(49.4 \%)$. After applying chi square test, it was found that there was statistically significant difference in the 
answers given by girls from the two schools in the routes of transmission like, needles, infected blood, sexual contact, toothbrush/razor, infected air, mother to child and staying together.

Table 9: Knowledge about modes of transmission.

\begin{tabular}{|lccc|}
\hline Modes of transmission & School A (\%) & School B (\%) & Total (\%) \\
\hline Needles & $24(32.4 \%)$ & $* 74(72.5 \%)$ & $98(55.7 \%)$ \\
\hline Infected blood & $30(40.5 \%)$ & $* 60(58.8 \%)$ & $90(51.1 \%)$ \\
\hline Sexual contact & $25(33.8 \%)$ & $* 62(60.8 \%)$ & $87(49.4 \%)$ \\
\hline Toothbrush/Razor & $24(32.4 \%)$ & $* 58(56.9 \%)$ & $82(46.6 \%)$ \\
\hline Infected air & $36(48.6 \%)$ & $* 25(24.5 \%)$ & $61(34.7 \%)$ \\
\hline Mosquito bite & $24(32.4 \%)$ & $21(20.6 \%)$ & $45(25.6 \%)$ \\
\hline Mother to child & $10(13.5 \%)$ & $* 34(33.3 \%)$ & $44(25 \%)$ \\
\hline Staying together & $24(32.4 \%)$ & $* 12(11.8 \%)$ & $36(20.5 \%)$ \\
\hline Bathroom, toilets & $12(16.2 \%)$ & $10(09.8 \%)$ & $22(12.5 \%)$ \\
\hline Utensils & $12(16.2 \%)$ & $09(08.8 \%)$ & $21(12 \%)$ \\
\hline Apparently healthy person & $42(56.7 \%)$ & $76(74.5 \%)$ & $118(67.1 \%)$ \\
\hline
\end{tabular}

\section{DISCUSSION}

\section{Knowledge about pubertal changes}

In our study it was found that maximum i.e. $122(69.3 \%)$ had incomplete knowledge about pubertal changes. Only $7(09.4 \%)$ of girls from school A had appropriate knowledge about pubertal changes as compared to 25 $(24.5 \%)$ from school $B$ and the difference was statistically significant.

These results were similar to a study done by Dorle AS et al in which only $09.25 \%$ of the girls had correct knowledge regarding secondary sexual characters, $81.50 \%$ had partial knowledge and $09.25 \%$ had no idea about pubertal changes. ${ }^{5}$

Table 10: Percentage of girls having knowledge prior to menstruation.

\begin{tabular}{|lll|}
\hline Study & Study place & $\%$ \\
\hline Present study & Mumbai & $146(92.9 \%)$ \\
\hline Nemade D $^{6}$ & Navi Mumbai & $217(100 \%)$ \\
\hline${\text { Verma } \mathrm{P}^{7}}^{2}$ & Bhavnagar & $656(88.1 \%)$ \\
\hline Dasgupta $^{2}$ & Kolkata & $108(67.5 \%)$ \\
\hline Omidvar S $^{8}$ & Mysore & $225(64.2 \%)$ \\
\hline Dorle AS & Babalkot, Karnataka & $28(25.9 \%)$ \\
\hline Udgiri R $^{9}$ & Bijapur slums & $18.4 \%$ \\
\hline Dhingra $\mathrm{R}^{10}$ & $\begin{array}{l}\text { Jammu Kashmir } \\
\text { Tribal }\end{array}$ & $0 \%$ \\
\hline
\end{tabular}

The maximum percentage of girls having knowledge prior to menarche were from study by Nemade D et al, Navi Mumbai and minimum (0\%) were from study done by Dhingra R et al, Jammu and Kashmir., ${ }^{3,10}$

\section{Stress, practices and believes regarding menstruation}

A total of $101(57.4 \%)$ of the girls had restriction to their activity during menses. $71 \%$ of girls from School A were following this practice which was significantly more as compared to $43.1 \%$ of girls in School B .When asked they said that they were made to stay at home or avoid playing. This was probably due to believes and as advised by mothers and grandmothers.

The restriction in activity were mostly in form of not visiting holy places, staying in isolation at home, not allowed to touch the idols of Gods, nor any family member, avoiding coming in contact with preserved foods like pickles and papads, in the fear of its spoilage. This difference between two groups could be due to difference in the level of education and cultural believes.

Similar findings were present in a study done by Nemade D et al (2009), where $100 \%$ girls reported that they do not visit holy places during menstruation and $51.77 \%$ girls reported that they are kept in isolation at home. ${ }^{6}$

Table 11: Percentage of girls having restriction of activity.

\begin{tabular}{|lll|}
\hline \multicolumn{1}{|c|}{ Study } & Study area & $\%$ \\
\hline Present study & Mumbai & $57.4 \%$ \\
\hline Dhingra R $^{10}$ & Jammu Kashmir Tribal & $91 \%$ \\
\hline${\text { Dasgupta } \mathrm{A}^{2}}^{2}$ & Kolkata & $85 \%$ \\
\hline Nemade D $^{6}$ & Navi Mumbai & $51.7 \%$ \\
\hline
\end{tabular}

Our study reveals that out of total 168 (95.5\%) girls who preferred regular bath to maintain their hygiene during menses, whereas $94.8 \%$ preferred hand wash to maintain 
hygiene. $111(63.1 \%)$ preferred washing genitalia with soap for hygiene during menses.

In a study by Nemade D, only 59 (29.95\%) girls reported that they wash their genitalia with soap and water whenever they change their cloth/sanitary pads. ${ }^{6}$ In their study, out of the 197 girls, $31(15.74 \%)$ girls used only cloth during menstruation, $80(40.61 \%)$ used only sanitary pads while $86(43.65 \%)$ girls used both sanitary pads and cloth during menses.

As regards to beliefs about menstruation, 56.2\% believed that menstruation cleans the body of dirty blood. A total of $73(41.5 \%)$ girls consider menstruation make girls weak. This was similar to a finding in a study done by Nemade D et al in where $72.35 \%$ girls felt that menstrual blood is impure. ${ }^{3}$

\section{Knowledge about family planning}

In present study a total of $51(29 \%)$ girls had complete knowledge about family planning; $13.5 \%$ of girls from school A which were significantly less as compared to $40.2 \%$ in school B. In a study by Tewari A, Tewari S conducted in Uttar Pradesh, two girl's colleges were randomly selected and 130 girls from class $11^{\text {th }}$ and $12^{\text {th }}$ were included. $^{11} 86 \%$ of the girls said that family planning means having 2 children and $14 \%$ said that it is meant by making plans for the family. The percentage of girls from their study, responding to this question correctly was higher than the present study. The reason could be that this study was conducted in senior classes.

\section{HIVIAIDS}

The present study reveals that a total $134(76.1 \%)$ girls had heard about HIV/AIDS. $88(86.3 \%)$ of girls from School B which was significantly more as compared to $46(62.2 \%)$ from School A.

In a study done by Singh A et al, total of 755 students (559 boys and 196 girls) of $9^{\text {th }}, 10^{\text {th }}$ and $11^{\text {th }}$ standard from all the schools of 29 districts of Gujarat were taken for the assessment of knowledge regarding HIV/AIDS through self-administered questionnaires. ${ }^{12}$ Approximately $35 \%$ of the respondents knew the full form of HIV and AIDS correctly. About half of the adolescents felt that both the sexes are equally vulnerable to HIV/AIDS. Only $35 \%$ of them were aware that HIV and AIDS are not synonymous. Here, more number of respondents were aware of HIV, probably because higher age group and inclusion of this topic in their curriculum.

\section{Modes of transmission}

When asked about the mode of transmission of HIV infection, $73.8 \%$ girls knew how HIV is transmitted. 46 $(62.2 \%)$ from school $\mathrm{A}$ and $84(82.4 \%)$ from school B. The most common answer given was transmission through needles $98(55.7 \%)$ followed by infected blood $90(51.3 \%)$ and sexual contact $87(49.4 \%)$.

Gaash B et al, conducted a study on a total of randomly selected 2,250 girls of Class XI and XII, of schools of Srinagar district. ${ }^{12}$ Among them $43.04 \%$ had no idea about the possible modes of transmission. Only $23.11 \%$ blamed it to the use of infected needles, $20.44 \%$ to sexual contact and $7.33 \%$ to infected blood. Only $3.56 \%$ were aware of the fact that HIV/AIDS could be transmitted from mother to child. Most of the respondents believed that HIV/AIDS could also spread through handshake $(82.22 \%)$, eating with the victim or sharing cups and utensils with him (64\%), or use of fomites (52\%). Only a few had the $(4.67 \%)$ knowledge that sharing toothbrushes or blades of patients could transmit the infection to others; the majority $(76.22 \%)$ was ignorant about the mode of transmission while a sizeable proportion $(19.11 \%)$ did not comment at all.

\section{CONCLUSIONS}

1. The present study was conducted in 176 adolescent girls from two English medium schools; school A (74 girls) catering to low socio-economic class and school B (102 girls) catering to high socio-economic class.

2. Only $18.2 \%$ girls had 'Appropriate' knowledge about pubertal changes. $09.4 \%$ from school A and $24.5 \%$ from school B. This difference was statistically significant. Most of the girls $69.3 \%$ had incomplete knowledge about pubertal changes.

3. A total number of $92.9 \%$ girls had some knowledge prior to their menarche about menstruation. $68.9 \%$ from school A as compared to $93.1 \%$ from school B. This difference in the two groups was statistically significant.

4. Restrictions during menstruation

a. $\quad 77.1 \%$ girls from school $\mathrm{A}$ and $43.1 \%$ from school B were following practice of restriction of activity during menses.

b. $81.1 \%$ girls from school $\mathrm{A}$ were having restriction to food as compared to $17.6 \%$ from school $\mathrm{A}$. The difference was statistically significant.

5. A total number of $95.5 \%$ girls were taking regular bath during menstruation and $94.8 \%$ practiced hand washing after using toilet.

6. Statistically significant number of girls from school B. $67.6 \%$ were seeking medical help for dysmenorrhea, excessive bleeding as compared to $29.7 \%$ from school A.

7. Most of the girls $51.2 \%$ got information about menstruation from their mothers.

8. The myths like 'Menstruation cleans the body of dirty blood' and 'Menstruation makes girl weak' were seen more commonly in girls from school A. $66.2 \%$ and $54.1 \%$ respectively as compared to $49.1 \%$ and $32.4 \%$ from school B. This difference was statistically significant. 
9. Only $33.5 \%$ girls; $13.5 \%$ from school A and $40.2 \%$ from school B had knowledge about family planning that was considered 'complete' for this study.

10. The most common answers given by the girls for method of transmission of HIV were needles by $55.7 \%$ followed by infected blood by $51.1 \%$ and sexual contact by $49.4 \%$.

\section{ACKNOWLEDGEMENTS}

Authors would like to thank the adolescent girls and their parents for their co-operation.

\section{Funding: No funding sources}

Conflict of interest: None declared

Ethical approval: Not required

\section{REFERENCES}

1. Karthiga V, Boratne A, Datta SS, Joice S, Abraham SB, Purty AJ. Menstrual problems and pattern of consultation among adolescent school girls in Pondichery. Indian Journal of Medical Specialties.02011;2(2).

2. Dasgupta A, Sarkar M. Menstrual Hygiene: How Hygienic is the Adolescent Girl?' Indian Journal of Community Medicine. 2008;33(2):77-80.

3. Nemade D, Seema A. Gujar R. Impact of Health education on knowledge and practices about menstruation among school girls of Kalamboli Navi Mumbai. Health and population; Perspectives and issues. 2009;32(4):167-75.

4. McManus A, Dhar L. Study of knowledge, perception and attitude of adolescent girls towards STIs/ HIV, safer sex and sex education: A cross sectional survey of urban adolescent school girls in South Delhi, India. Bio Med Central Women's Health. 2008;8(12):13.
5. Dorle AS, Hiramath. Puberty changes in secondary school children of Bagalkot,Karnataka. Journal of Clinical and Diagnostic Research. 2010;(4):3016-9.

6. Verma P, Pandya C, Ramanuj V, Singh M. Menstrual Pattern of Adolescent School Girls of Bhavnagar (Gujarat); NJIRM (National Journal of Integrated Research in Medicine). 2011;2(1).

7. Omidvar S, Begum K. Factors influencing hygienic practices during menses among girls from south India'- A cross sectional study. International Journal of Collaborative Research on Internal Medicine \& Public Health. 2010;2(12);411-23.

8. Udgiri R, Angadi MM, Shailaja, Sorganvi V. Knowledge and practices regarding menstruation among adolescent girls in an urban slum, Bijapur. Indian Med Assoc.2010;108(8):514-6.

9. Dhingra R, Kumar A, Kour M. Knowledge and Practices Related to Menstruation among Tribal (Gujjar) Adolescent Girls in Jammu and Kashmir. Ethno-Med. 2009;3(1):43-8.

10. Ahuja A, Tewari S. Awareness of pubertal changes among adolescent girls. J Fam Welfare. 1995;41:46-50.

11. Singh A, Jain S. Awareness of HIV / AIDS among school adolescents in Banaskantha district of Gujarat. Health and Population: Perspectives and issues. 2009;32(2):59-65.

12. Gaash B, Ahmad M, Kasur R, Bashir S. Knowledge, attitude and belief on HIV / AIDS among female senior secondary students in Srinagar district of Kashmir. Health and Population Perspectives and Issues. 2003;26(3):101-9.

Cite this article as: Sathe PP, Sathe PP, Kotnis SD, Mangulikar SK. Assessment of knowledge of reproductive health of adolescent school girls from 13-16 years with special reference to HIV-AIDS. Int J Community Med Public Health 2016;3:340-6. 